\title{
Research on Application of Micro-Lectures Mode Based on Information Age in Writing Teaching of College English
}

\author{
Ming Zhao \\ College of Foreign Languages, Bohai University, Jinzhou 121013, China
}

Keywords: Information age; Micro-lectures; Writing teaching of college English

\begin{abstract}
In the background of the information age, with the gradual integration of some technology elements in the teaching, micro-lectures came into being. It can not only suit for the need of modern development but also contribute to promoting the reform of college English teaching to carry out the writing teaching of college English by focusing on micro-lectures. This paper expounds in detail the specific application of micro-lectures mode in writing teaching of college English.

Preface: With teaching videos as its main teaching content, supported by technology, micro-lectures is refer to a mini-course for a certain knowledge. Generally, it is charactered by the video carrier and the short and simple structure. It can help the students to better concentrate on the teaching and facilitate the students to carry out English writing at anytime and anywhere. The following is a detailed description of micro-lectures mode in writing teaching of college English.
\end{abstract}

\section{Current Situation of Writing Teaching of College English}

In light of the present stage, there are still some problems which can not be ignored in writing teaching of college English. Firstly, from teaching equipment, the proportion of teaching equipment has been unable to meet demand of the expansion of college enrollment. In such a situation, it is hard to improve the quality of writing teaching of college English in the background of the information age. Secondly, from teaching method, for many teachers, the teaching is mainly carried out in the traditional way of "teachers are to teach while students are to listen". In this mode of teaching, students slowly lose their interest in English writing learning. Lastly, from teaching hours, the teaching hours for non-English majors usually is 2 teaching hours each week. Due to the limited teaching hours, it is very hard to impart lots of knowledge points to students and accomplish successfully teaching tasks. In a word, the teaching effect of college English writing is not very satisfactory. Teachers should be combined with the development trend of the information age and reform the writing teaching mode of college English.

\section{Importance of Micro-Lectures in Writing Teaching of College English}

Charactered by teaching video, short lectures and flexible study time, micro-lectures is beneficial for teachers to make a reasonable course arrangement. At the same time, because of the rich micro-lectures resources, it can better satisfactory the development demand of the information age to apply micro-lectures in writing teaching of college English. In the background of the information age, the products of the information age such as WeChat and microblog are favored by college students, and who are more willing to accept the vivid, rich and short teaching content. In case of application of micro-lectures in writing teaching of college English, it can help to realize the imparting of knowledge points and concentrate students' attention to use the teaching mode of short video. In addition, it can change the traditional teaching mode of "teachers are to teach while students are to listen" and promote teaching reform through new teaching methods such as classroom interaction and exercises out of class to apply micro-lecture mode in writing teaching of college English. Besides the above, in case of application of micro-lectures in writing teaching of college English, it is convenient for teachers to recommend various micro-lectures for students through WeChat group and QQ group to lead students to independently analyze the writing characteristics of English composition and actively analyze the sample writing with their time after 
class, and have discussion with their classmates and teachers in class, thus establishing a good relationship between teachers and students. In other words, it is beneficial to apply micro-lectures in writing teaching of college English. Teachers should scientifically use this teaching method to make writing class of college English more vivid, interesting and infectious, and further develop students' capability of English writing, improve students' writing level and help students avoid the writing problems such as "how to start writing".

\section{Specific Application of Micro-Lectures Mode Based on Information Age in Writing Teaching of College English}

Writing Teaching Preparation. In writing teaching of college English, due to valuable teaching time, before writing, students should be provided with effective guidance, and teachers should pay more attention to introduce the relevant knowledge points. For example, when a teacher teach his students how to write the Topic sentence, for better teaching effect, he firstly analyzed the teaching goal, object and content of the course. In analysis, it is the teaching goal to clearly teach students to how to write the topic sentence, and it is a teaching difficulty how students write the Topic sentence in accordance with the Topic. Then, the teacher began to make the micro-lectures. The pictures about fish were used to express the composition structure. Fish head, belly and tail were respectively used to represent the topic sentence, supporting sentences and concluding sentence. The concept of topic sentence is clarified for students in text, i.e. "Topic: sentence to tell the reader what the paragraph is mainly about.....". After introduction of the concept of topic sentence, with "The importance of reading widely" as an example, the teacher gave a detailed explanation of writing method and importance of topic sentence to students. Several exercise about topic sentence were designed at the end of micro-lectures video. Lastly, the teacher shared the micro-lectures in WeChat group of class and asked students to independently watch the video before writing class. After watching the video, students naturally master the writing method of topic sentence and have an excellent basis for writing teaching class of English. At the same time, during the recording of micro-lectures, to create an atmosphere of 1 on 1, concentrate students' attention and tap students' potential subject consciousness, the teacher paid much attention to the practical phrases such as "we" and "you" rather than the phrases such as "everybody" and "you".

With teaching of the composition title "We are what we read" as another example, a teacher found that many students had no clue in their English composition writing processes due to abstractness of the title "We are what we read". In response to this situation, the teacher began trying to lead students by playing the micro-lecture video of 8 minutes. The video content is a campus interview, and in which, college students were asked what are their favorite books and what is the influence of reading, and some famous works and English sayings are recommended for the students ${ }^{[1]}$. After watching the micro-lectures, students mastered some written materials, had writing thought and successfully finished the composition writing with title of "We are what we read".

From the above case, the application of micro-lectures mode in writing class of college English can not only demonstrate to students the relevant knowledge points in a visual and vivid form to deepen students' understanding on knowledge of English writing but also share some writing materials with students to make them better master the direction of English writing and avoid the writing problems such as being devoid of content. In a word, in writing class of college English, micro-lecture has an important guiding role. Teachers should be good at implying micro-lectures mode in teaching to allow students to accept effective education, exactly master writing and understand the main points and significance of writing in advance when they feel there is no way to begin.

Writing Teaching Operation. In writing teaching of college English, to better arouse students' writing interest, teachers should change the situation that teacher only pay attention to the scores after students separately finished their writing. They should provide students with more opportunities for interaction through the mode of micro-lectures to make students to better arrange thoughts and information for polishing their compositions through communication with each other. For example, when a teacher teach students how to write a descriptive text for result, to arouse 
students' writing interest and make students to master the writing methods for descriptive text, he demonstrated to students the following three questions in class:

1. What is effect essay?

2. What are the three characteristics of effect essay?

3. What are the effects of watching too much TV?

After that, students were divided into several groups of four, and students in groups were asked to discuss the above questions. In the actual interaction process, students gradually found out that "Effect essay discusses the results of an event or situation", understood the characteristics of descriptive text for result and learned to make an outline about "Effects of watching too much TV" with a mind map.

From the above case, the application of micro-lectures video in writing teaching of college English can not only provide students with more interaction opportunities for communication and discussion on issues related to English writing but also arouse students' English writing interest to devote themselves entirely to English writing.

In writing class of college English, to greatly improve the teaching effect, the writing mode should be readjusted after the introduction of micro-lectures mode into class. Firstly, teachers should provide students with guidance on discussion and interactive negotiation. Secondly, teachers should ask students to independently finish online writing, monitor the writing effect and pay attention to mutual review and evaluation between classmates. Lastly, teachers should be responsible for the revisions of composition in class and the final composition ${ }^{[2]}$. For example, when a teacher teach students how to write English composition, according to the overlapping points of www.pigai.org and micro-lectures teaching, he firstly assigned a composition topic in class, and then made the micro-lectures with teaching resources and uploaded it to www.pigai.org. Lastly, the teacher asked students to finish their writing tasks online. The teaching mode of English writing can break through time and space limitations to provide students with more opportunities for actual training.

Writing Teaching Evaluation. Micro-lectures can be used after writing teaching class of college English as a support. It can help students to enhance the memory of knowledge points when they are hard to remember the knowledge points for writing after class. In addition, application of micro-lectures can help to obtain better effect of after-school tutoring by replacing the past tutoring mode that teachers must tutor students face to face with the tutoring mode of short micro-lectures video.

After class, to improve the students' mastering degree of knowledge points for English writing, teachers should assign some tasks to students with help of micro-lectures video to make them to really understand the learning content and develop good writing ability ${ }^{[3]}$. For example, after detailed explanation of knowledge points in writing the composition with title of "Introducing a place", he made a micro-lectures video with all knowledge points. In the video, the possible words such as location, area, transport, population, history and places of interest were firstly demonstrated for students. Then, he demonstrated the following questions to students:

I. Please fill in the common sentences and phrases.

China is a developing country

China 5000

II. Please translate the following sentences.

The history of the city dates back to Tang dynasty.

The population of our city is increasing year by year.

Eighty percent of the population here are farmers.

It is very convenient for you to come to our city. 
III. Please write a short passage about Guangzhou according to the following.

\begin{tabular}{|l|l|}
\hline Name & "Flower City" \\
\hline History & over 2,200 years \\
\hline Population & more than 10 million people \\
\hline Area & $7,434.4$ square kilometers \\
\hline Location & neighboring South China Sea \\
\hline $\begin{array}{l}\text { As the birthplace of the Maritime Silk Road, Guangzhou is full of tourist attractions } \\
\text { for lots of tourists from home and abroad. }\end{array}$ \\
\hline
\end{tabular}

After watching the micro-lectures video, students began to carry out the corresponding consolidation exercise in accordance with the content of the video, and finally mastered some knowledge points for English writing.

From the above case, in the consolidation phase after writing teaching class of college English, the application of micro-lectures can contribute to multiple review of the relevant knowledge and timely settlement of the remaining problems for students benefiting from its characteristic of replay. In addition, teachers can carefully choose some exercises to provide better exercise opportunities for students for their study growth ${ }^{[4]}$. But during the practice teaching, in order to gain the high efficiency of teaching, teachers should make the micro-lectures video based on the principles of objectivity, reliability and comprehensiveness, and demonstrate to students a certain knowledge point for English writing with multiple methods such as teaching, interaction between teachers and students, student activities, performance and discussion to make teaching class more vivid and interesting to concentrate students' attention and improve the teaching efficiency of English writing.

\section{Conclusion}

In conclusion, micro-lectures mode is significant to the writing teaching of college English. To improve the writing teaching effectiveness of college English, micro-lectures mode shall be applied in the three stages: before class, during class and after class. In this way, more personal and diverse writing teaching of English must contribute to improvement of the students' learning effect and enhancement of the students' writing ability training.

\section{References}

[1]Jingyi SUN. Research on the Teaching Strategies of College English Writing Under the Guidance of Schema Theory[J]. Cross-Cultural Communication, 2016, 12(4): 42-45.

[2]Jiaxin Xing. An Empirical Study of Applying E-mail Exchange to College English Learners' Writing[J]. Journal of Language Teaching and Research, 2014, 5(4): 856-864.

[3]Fushan Sun. The Application of Schema Theory in Teaching College English Writing[J]. Theory and Practice in Language Studies, 2014, 4(7): 1476-1482.

[4]Jingyu Liu. College English Writing Teaching Design Based on Constructivist Mode[J]. Open Journal of Modern Linguistics, 2015, 05(01): 42-47.

[5] Peng L. Cost heterogeneity and peak prediction in collective actions [J]. Expert Systems With Applications, 2017, 79: 130-139. 